\title{
Una historia de la música colonial hispanoamericana
}

Waisman, L. J. (2019). Buenos Aires: Gourmet Musical Ediciones. 480 páginas.

- Javier Marín-López

Universidad de Jaén, Jaén, España

marin@ujaen.es

La entrada del siglo XXI ha planteado a los estudiosos de la música colonial algunos retos que, lejos de ser exclusivos de este campo de conocimiento, afectan al conjunto de las Ciencias Humanas y Sociales. De un lado, la acelerada fragmentación y atomización de conocimientos, en parte consecuencia de la creciente especialización de la investigación y el número cada vez mayor de fuentes, publicaciones y enfoques; esta circunstancia, unida a la existencia de incomprensibles vacíos, acaba por conformar un cuadro confuso, disperso y segmentado de la realidad que queremos estudiar. De otro, la crítica radical de paradigmas epistemológicos y formas totalizadoras y lineales de escritura histórica que, además de instrumentalizar metodologías, ocultan el carácter particular y sesgado de sus métodos, aunque lo hagan por medio de un lenguaje y unas categorías supuestamente universales y neutras. ¿Cómo encarar la compleja narración de los "grandes procesos" de la música colonial hispanoamericana ante un inabarcable manantial de estudios -algunos de muy difícil acceso-, amenazadoras zonas ignotas y la "crisis" terminal de paradigmas en la historia? ¿Cómo hacerlo en un contexto global post-neo colonial?

Estos han sido algunos de los enormes desafíos que ha tenido que afrontar Leonardo J. Waisman para la redacción de Una historia de la música colonial hispanoamericana, bienvenida y esperada monografía publicada por la editorial Gourmet Musical Ediciones en 2019. Su autor, conocido en el campo de los estudios de la música colonial por sus trabajos sobre las misiones jesuíticas, culmina con esta obra un proyecto de largo alcance cuyos orígenes se remontan a sus primeras publicaciones sobre el tema, hace casi tres décadas (Waisman, 1991). Según declara, su propósito es ofrecer un "esbozo de la vida musical en la América hispana entre los reinos de Felipe II (que accedió al trono en 1558) y Carlos IV (que abdicó en 1808)" (p. 11); para ello toma por válido el concepto de música colonial, que identifica con el conjunto de prácticas y repertorios musicales de raíz europea (ya sean académicos o populares), cultivados por peninsulares, criollos, indios, negros y sus subsiguientes cruces (excluyendo las músicas consideradas étnicas), en un contexto de clara asimetría de poderes, como se nos recuerda con la cita al semiólogo Walter Mignolo. La ambición intelectual de la empresa y la amplitud geográfica y cronológica del objeto de estudio, unido a la falta de monografías previas que pudieran servir como modelo, evidencia la relevancia histórica de la tarea brillantemente emprendida por Waisman, quien nos brinda la primera gran síntesis crítica en castellano sobre la música colonial hispanoamericana, publicada en forma de libro. ${ }^{1}$

${ }^{1}$ El libro divulgativo del músico, director coral y periodista Ramiro Albino (2016), basado en la concatenación de citas tomadas de diversos autores (entre ellos el propio Waisman), no se ubica en el campo de la investigación propiamente musicológica. 
Tras la necesaria Introducción, la obra se estructura en tres bloques o partes, que se dedican grosso modo a los siglos XVI (capítulos 1-4), XVII (capítulos 5-8) y XVIII (capítulos 9-13). Cierran el volumen dos apéndices: el primero, de 93 páginas, ofrece biografías de 210 compositores activos en Hispanoamérica entre 1550 y 1808, preparadas por Luciana Giron Sheridan y Lucas Reccitelli, miembros del Grupo de Musicología histórica de Córdoba; ${ }^{2}$ el segundo, mucho más breve (poco más de dos páginas), presenta definiciones cortas de algunos instrumentos musicales utilizados durante el periodo. Sirve de colofón un completo (e imprescindible en obras de esta naturaleza) índice de nombres, instituciones, géneros y otros términos musicales. Los bloques primero y tercero son versiones revisadas y actualizadas de textos escritos por el autor en 2000 y 2009, publicados años después en el marco de proyectos editoriales españoles (Waisman, 2004a y 2014). El bloque central, dedicado al siglo XVII, fue escrito posteriormente ad hoc con el propósito de completar la obra y contiene amplias secciones dedicadas al análisis estilístico del repertorio que están ausentes en los otros dos bloques, aunque el conjunto nunca pierde de vista el peculiar contexto histórico, social y cultural de los virreinatos indianos. ${ }^{3}$

Los tres bloques mencionados abordan y resuelven satisfactoriamente problemáticas de todo tipo, tanto teóricas como prácticas. Quizá la

\footnotetext{
${ }^{2}$ Sobre la conformación de este grupo de investigadores en la Universidad Nacional de Córdoba bajo el liderazgo del mismo Waisman, véase Restiffo (2019). Varios miembros del Grupo también colaboraron en un volumen de este investigador inmediatamente anterior al aquí reseñado (Waisman, 2015).

${ }^{3}$ La articulación de textos originalmente independientes, escritos en diversos momentos y con distintos criterios, genera pequeñas disfunciones al integrarse en una única narrativa; sobre esta cuestión y las divergencias de los bloques 1 y 3 con respecto a las versiones anteriormente publicadas, véase Pérez González (2019, pp. 139-141).
}

mayor de ellas derive de la necesidad de integrar en un único relato distintos tipos de música cultivada en diferentes territorios y épocas a cargo de disímiles grupos sociales y étnicos con divergentes respuestas y activos en cambiantes contextos socio-políticos. Lejos de convertir esta heterogeneidad en una traba metodológica, el autor adopta conscientemente un modelo narrativo multifocal que, pese a una narrativa subyacente de corte cronológico, descompone el relato en una trama de varias corrientes interconectadas. Ello permite a Waisman liberarse de un tratamiento totalizador y absoluto, y seleccionar los argumentos y protagonistas de cada capítulo, sorteando tácticamente los grandes vacíos existentes para concentrarse en los materiales a los que ha tenido acceso. En coherencia con esa estrategia, el resultado es una historia descentralizada y plural, con diversos focos y encuadres, que se aproxima de manera creíble y bastante personal a una realidad compleja y ecléctica, imposible de reducir a una única narrativa. ${ }^{4}$

Cada una de las tres partes muestra una estructura similar: una introducción histórica (capítulos 1, 5 y 9) que presenta sintéticamente las coordenadas en las que se desenvuelve la práctica musical asociada a la "república de indios", es decir, parroquias, doctrinas rurales y reducciones (capítulos 3, 6 y 10), por un lado, y la "república de españoles" (capítulos 2, 7 y 11) con su contingente de instituciones blancas, por otro; se dedican secciones diferenciadas a la vida musical de otros ámbitos urbanos en los bloques primero y tercero (capítulos 4, 12 y 13), en tanto que el segundo incluye un amplio capítulo analítico (capítulo 8). La extensión de los capítulos es bastante desigual: las 72 páginas del citado capítulo 8 contrastan con las 8, 10 y 13 páginas de los capítulos 4, 12

${ }^{4}$ El propio autor justifica in extenso su enfoque teórico en Waisman (2017). 
y 13, respectivamente, lo que genera un fuerte desequilibrio que es consecuencia parcial del menor conocimiento sobre prácticas musicales profanas. La aproximación adoptada por el autor en la construcción de su relato permite y hasta invita a lecturas no secuenciales, aunque la organización de la narrativa es clara: los proyectos institucionales de peninsulares y criollos de un lado, y las diversas resistencias a su implantación por parte de los naturales y castas de otro, en medio de un proceso no lineal ni homogéneo, con múltiples bifurcaciones, fases inmóviles y vueltas al pasado, sujeto a una amplia y variada casuística de coyunturas locales.

El primer bloque, que cubre la segunda mitad del siglo XVI, ofrece una sinopsis del lento y fascinante proceso de aculturación reflejado en la diversificada vida musical americana y relata algunas de las numerosas situaciones de conflicto y rechazo por las que atravesó el proyecto utópico ideado por los europeos. La práctica musical más prestigiosa era la asociada a las catedrales, aunque su implantación en los Reinos de Indias fue a costa de una radical transformación del modelo peninsular: la fuerte injerencia de autoridades eclesiásticas en asuntos musicales, traducida en un predominio de los nombramientos directos y una ausencia casi estructural de oposiciones; la presencia constante de músicos no ordenados y casados (incluso en los puestos de mayor responsabilidad); la tendencia general a una menor movilidad (debido a las grandes distancias) y a un marcado localismo; y la contratación ocasional de ministriles indios, en los últimos peldaños del escalafón catedralicio. Entre líneas emerge una interacción constante entre las distintas esferas de la práctica musical y una revalorización del papel de los naturales, negros y mestizos como agentes activos de la cultura colonial y verdaderos protagonistas de un proceso de negociación simbólica y “apropiación resistente" (p. 87), por momentos sutil y por momentos violento, como demuestra el movimiento del taki onqoy.

El segundo bloque, el más extenso, se dedica al siglo XVII, visto tradicionalmente como una etapa de transición y sin personalidad propia que ahora es rehabilitada y considerada como una "verdadera edad de oro de la polifonía del Nuevo Mundo" (p. 139). Waisman invierte aquí el orden de los elementos, poniendo en primer lugar el capítulo dedicado a la "república de indios"; ello quizá con la idea de conceder mayor centralidad narrativa a los naturales y sus capillas musicales semiprofesionales, como ya hizo Geoffrey Baker en su estudio sobre el Cusco colonial (Baker, 2008; reseñado, entre otros, en Marín-López, 2009). Pese a lo fragmentario y localizado de las evidencias disponibles, resulta loable el esfuerzo por bosquejar procesos y tendencias de más largo alcance. La miríada de músicas catequísticas, civiles y militares de los pueblos de indios y las reducciones de frontera (en ocasiones con un estilo musical muy distinto al europeo), tenía su contrapartida en la sostenida actividad desplegada por la población blanca en capillas catedralicias, conventuales y monacales, aunque los límites en estos ámbitos se veían continuamente transgredidos. La imposibilidad de ofrecer un panorama abarcador (se han perdido, por ejemplo, todas las grandes bibliotecas misionales del siglo XVII) lleva a Waisman a concentrarse en un género mainstream para la música colonial como el villancico, ofreciendo un estudio estilístico monográfico que se articula en tres momentos: el repertorio del primer cuarto del siglo XVII de Gaspar Fernández, representante del villancico como canción; los ciclos de Navidad de Juan Gutiérrez de Padilla, con quien se produce una cristalización de modelos a mediados del siglo; y la producción de Tomás de Torrejón y Juan de Araujo, quienes reelaboran y ampliaron los modelos heredados. 
El tercer bloque se configura en torno a la idea de modernización de la vida cultural y artística gracias a la llegada de las nuevas tendencias italianas y francesas, matizando en alguna medida el protagonismo de las instituciones eclesiásticas. Se ofrece aquí una valiosa caracterización de la vida musical en las reducciones americanas, el perfil general del repertorio italo-germano predominante y su pervivencia -y consiguiente transformación y re-semantización- durante largos periodos de tiempo. En el caso de las ciudades de españoles, se delinean las prácticas musicales formales e informales, religiosas y profanas, compartidas por determinados núcleos urbanos, así como sus marcadas especificidades (se afirma que en algunas catedrales de provincia, como la de Córdoba del Tucumán, directamente no había servicios con "canto de órgano", p. 272). En paralelo, se ofrece una síntesis de las principales personalidades y corrientes musicales, desde el estilo híbrido hispano-italiano de las primeras décadas de la centuria a la recepción del estilo galante años después. En este contexto, se dedican relevadoras páginas al criollismo, que Waisman vincula con el surgimiento de una identidad local y que se traduce, a nivel compositivo, en un control consciente de las novedades recibidas y sus formas de integración en la tradición hispana por parte de algunos compositores. Pese a ello, no puede hablarse, en el caso de la América colonial, de escuelas o tendencias específicamente americanas (pp. 174-175).

Son muchos los aspectos positivos que emanan tras la lectura de esta particular obra. Uno de los más obvios e inmediatos es la preciosa labor de síntesis de abundantes y excepcionalmente dispersas investigaciones previas, cuya utilidad relativa no siempre es evidente y que aquí queda redimensionada al integrarse en una red de significados y ponerse en relación con otros elementos. Esto constituye en sí mismo un aporte no menor en el caso de la música colonial, en la que diversos condicionantes lastran cualquier intento de síntesis interpretativa: la enorme extensión y la marcada fragmentación geográfica del espacio hispanoamericano, en el que cada país, región o archivo constituye una historia aislada y autocontenida; el fuerte peso de la ideología nacionalista en la escritura de las primeras historias de la música de cada país, lo que complica el establecimiento de relaciones entre territorios estancos; y la dificultad misma no ya de acceder sino simplemente de estar al día del creciente número de publicaciones sobre música colonial, lo que convierte el rastreo bibliográfico, como sentenciara lapidariamente Gerardo V. Huseby en un "penoso proceso detectivesco, cuyos frutos son necesariamente incompletos y se hayan en gran medida sujetos al azar" (1993, p. 60). ${ }^{5}$

Otro aspecto destacable de esta Historia es el cuidadoso equilibrio y la integración continental de casos provenientes de los virreinatos de Nueva España y del Perú, las dos demarcaciones político-administrativas de la América española durante gran parte del periodo estudiado. Para ello, el autor se apoya en un amplio elenco de fuentes primarias y secundarias que somete a crítica hermenéutica. Algunas de ellas han sido poco transitadas por la musicología, lo que le permite -por ejemplo- sentar las bases para una futura historia económica de la música catedralicia basándose en el historiador Enrique Dussel (pp. 136-142, pp.150-151), dar voz a la historia

\footnotetext{
${ }^{5}$ Las palabras de Huseby no han perdido su vigencia en la actual era de Internet. Huseby fue el editor general de la Bibliografía Musicológica Latinoamericana, un proyecto conjunto de la Asociación Argentina de Musicología y la Revista Musical Chilena del que se publicaron dos volúmenes en tres números monográficos de la Revista Musical Chilena (177 [enero-junio 1992], 178 [juliodiciembre 1993] y 181 [enero-junio 1994]). Un proyecto paralelo en el tiempo, específicamente centrado en el ámbito colonial, fue liderado por Cetrangolo y Giuliani, 1992.
} 
musical de los indios, superando la tradicional visión hispanocéntrica (capítulos 3, 6 y 10) o plantear la primera gran síntesis sobre el criollismo musical a escala continental (pp. 289-306). ${ }^{6}$ No estamos ante una mera acumulación de datos: la información aparece inteligentemente seleccionada, organizada, jerarquizada y reducida a principios explicativos claros y precisos, con un ágil estilo de escritura y una prosa amable que cautiva y atrapa al lector. Las unidades de información se yuxtaponen, enlazan y complementan, como teselas de un mosaico, hasta ofrecer un cuadro de conjunto en el que, inevitablemente, se producen algunas asimetrías territoriales, ya sea por la escasa evidencia disponible para los periodos más tempranos en determinadas regiones (como el Caribe insular), o por las dificultades de acceso a estudios y ediciones particulares; sirvan como ejemplo de esto último trabajos anteriores en torno a la Real Audiencia de Quito ${ }^{7}$ o la publicación de partituras procedentes de las actuales repúblicas de Colombia, Venezuela, Guatemala y Bolivia, ${ }^{8}$ por mencionar algunos casos selectos.

\footnotetext{
${ }^{6}$ Algunos recursos para hispanizar el estilo italiano, así como ejemplos de piezas con textura "hueca" de 2-3 voces agudas y acompañamiento de bajones, similares a las encontradas en $\mathrm{Su}$ cre, también están presentes en compositores peninsulares como José Martínez de Arce o Juan Francés de Iribarren. ¿Hasta qué punto el empleo de bajones obligados en diálogo con un grupo reducido de voces refleja un americanismo o constituye una simple evolución estilística de los "coros de ministriles", típicos del villancico hispano del siglo XVII, que mantuvieron su vigencia hasta finales del siglo XVIII, en particular en géneros como las lamentaciones y los versos de Miserere?

${ }^{7}$ Cf. Harrison (1973); Cazorla (2000) y Godoy Aguirre (2004).

${ }^{8}$ Véase Bermúdez (1988) y Restrepo (1996) para Colombia; la mítica edición de Plaza (1942-43) -considerada la primera edición monumental de música colonial- para Venezuela; y Lehnhoff (1990), que incluye transcripciones de diecisiete obras del guatemalteco Rafael Castellanos no incluidas en la traducción española de 1994. Resulta sorprendente no encontrar referenciada ninguna de las numerosas ediciones de Piotr Nawrot publicadas por la Cooperación Española en Bolivia, la Editorial Verbo Divino y el Fondo Editorial APAC, y que Waisman cita en otros trabajos de su autoría.
}

Entre las contribuciones más originales y valiosas está la importancia concedida al análisis del repertorio, una asignatura pendiente de la musicología colonial y un aspecto que separa el libro de Waisman de síntesis previas realizadas en inglés como el capítulo de Robert Stevenson para The Cambridge History of Latin America (Stevenson, 1984); el primer borrador, aún inédito y nunca completado, que Samuel ClaroValdés presentó en 1985 para el proyecto Music in the Life of Man: A World History liderado por Barry S. Brook, posteriormente redenominado The Universe of Music: A History (Claro-Valdés, 1985); ${ }^{9}$ o la más reciente pero problemática contribución de Daniel Mendoza de Arce (2001; reseñada, entre otros, en Restiffo, 2010). Aunque los ejemplos musicales se concentran fundamentalmente en el capítulo 8 (acaso el de mayor contribución original), otros muchos capítulos contienen brillantes discusiones estilísticas y comentarios valorativos personalizados de diversos compositores. Si bien las ediciones estaban ahí, era necesario analizarlas, interpretarlas y articularlas metódicamente a la luz de los recursos musicales en boga, la teoría coeva y los cambiantes sistemas modales y tonales, que el autor conoce y maneja con soltura (pp. 180184). Las aproximaciones a las chanzonetas y villancicos de Gaspar Fernández y Juan Gutiérrez de Padilla resultan particularmente lúcidas y marcan un hito en el estudio de estos maestros,

\footnotetext{
${ }^{9}$ El fallecimiento de Samuel Claro-Valdés en 1994 hizo que Malena Kuss, la directora ejecutiva del proyecto desde 1996, encargase a Stevenson la contribución dedicada al periodo colonial, que fue completada en 1999; se trata de una versión notablemente revisada y expandida de su texto de 1984 (Stevenson, 1984), ahora titulada "Music in the American Viceroyalties" y ya con ejemplos musicales (Stevenson, 2020). Este trabajo estaba destinado a publicarse en Music in Latin America and the Caribbean: An Encyclopedic History, editado por Malena Kuss, y del cual se imprimieron los dos primeros volúmenes en 2004 y 2007. El ensayo panorámico de Stevenson será dado a conocer en breve, en edición electrónica, en el tercer volumen de esa serie. Agradezco esta información a Malena Kuss.
} 
haciendo aflorar su gran variedad y sofisticación de recursos técnicos y configuraciones formales.

La sólida formación internacional de Waisman en repertorios "centrales" le proporciona un amplio e informado marco de referencia. ${ }^{10}$ No sorprende, por ello, que en su caracterización de determinados maestros coloniales recurra a Giacomo Carissimi y la música italiana de mediados del siglo XVII (pp. 221, 226, 235) o al intermezzo italiano de principios del siguiente (p. 238), o a que, en el trabajo compositivo por módulos o bloques constructivos yuxtapuestos característico del villancico en la segunda mitad del Seiscientos, establezca relaciones con géneros europeos tan distintos como el madrigal del siglo XVI o la sinfonía del siglo XVIII (pp. 215-220). Pero lo más significativo es que en el patrón de análisis desplegado se deja a un lado la permanente preocupación por modelos absolutos de calidad artística y la obsesiva comparación con tipos ideales europeos; muy al contrario, Waisman se muestra partidario de comprender la música colonial en sus propios términos, características y condicionantes, como reflejo de una complejidad de estrategias técnicas y negociaciones estéticas entre modelos cosmopolitas y usos locales que conviven en un universo cambiante, lleno de contrastes y fértil en sincretismos.

La tesis central de Waisman es escribir una historia descentralizada y alternativa de la música colonial. Sin embargo, los ejes epistemológicos presentes y ausentes acaban por configurar un relato en cierto modo canónico, tradicional y

\footnotetext{
${ }^{10}$ Waisman realizó su tesis sobre el madrigal renacentista italiano (Waisman, 1988) y es autor de varias ediciones sobre ópera bufa del siglo XVIII publicadas por el Instituto Complutense de Ciencias Musicales. Adicionalmente, ha dirigido conjuntos de música antigua como Musica Segreta (con el que grabó 2 CDs de música colonial en 1992 y 1994), Vox Antiqva y Compagnia Scaramella, entre otros, lo que le permite tener un conocimiento práctico del repertorio.
}

hasta contradictorio, sobre todo cuando se pone en diálogo con publicaciones previas del autor. Así, aunque él mismo había insistido en la necesidad de revisar el uso de los conceptos de "autor" y "obra" al hablar de música colonial (Waisman, 1998) y había subrayado los problemas asociados a la escritura de biografías (Waisman, 2009), los sujetos principales del relato son convencionales maestros de capilla activos en las Indias y sus creaciones vocales polifónicas, relegando los repertorios no escritos, la música instrumental o el omnipresente y anónimo canto llano a una posición bastante marginal. ${ }^{11}$ El hecho de introducir un apéndice con entradas biográficas de orientación enciclopédica y los criterios mismos de selección son sumamente reveladores del rol central concedido al binomio autorobra: incluye "solo músicos compositores [...] cuya música se conserve” (p. 330); además, se aplican con cierta laxitud y contienen algunas fallas, omisiones e inconsistencias, como el propio Waisman reconoce en su presentación (p. 330). ${ }^{12}$ El uso de la terminología histórico-

\footnotetext{
${ }^{11}$ Sobre estos temas no había demasiados estudios antes de marzo de 2014, cuando se cerró la redacción del volumen, pero en el caso del canto llano se disponía de la visión de conjunto ofrecida por Stevenson (1968, pp. 172-199), que estimuló la realización de estudios monográficos sobre impresos y manuscritos específicos (Housty, 1970; Duncan, 1975; Madsen, 1984).
}

${ }^{12}$ A modo de ejemplo: se ubica el fallecimiento de fray Cristóbal de Ajuria en México y no en Chile (p. 333); se indica que Francisco de Vidales fue maestro de capilla en la Catedral de México entre 1648 y 1654, años en los que el maestro titular era su tío Fabián Pérez Ximeno (p. 417); se afirma que Antonio Durán de la Mota (p. 360), Andrés Flores (p. 365), Eustaquio Franco Reboyo (p. 367), Pablo Grandon (p. 370) y Estanislao Leyseca (p. 380) tienen obras conservadas en el denominado "Cancionero mariano de Charcas", que no constituye ninguna fuente histórica, sino una recopilación de letras cantadas en Charcas dedicadas a María publicada modernamente (2009) por Andrés Eichman. Por otro lado, varios compositores con obra conservada anterior a 1808 quedan fuera del nomenclátor, como Melchor Tapia Zegarra (ca. 1755-ca. 1818) o José Francisco Delgado (1771-1829), activos en Lima y Ciudad de México, respectivamente, y objeto de sendas tesis doctorales en la década de 1970 (Eyzaguirre, 1973; Nichols, 1975); sí se incluye, en cambio, a compositores de cronología incluso más tardía como José Antonio Picassarri (1769-1843) o Manuel Ro- 
estilística europea también está presente y sirve para rotular capítulos como el 7 ("la floración del barroco musical"), aunque el mismo autor había advertido en otros textos lo peliagudo de su aplicación al medio musical americano (Waisman, 2016, p. 67). Por último, el papel crucial de los intérpretes y las prácticas de ejecución, así como su significado para los oyentes del periodo colonial, son aspectos mencionados de pasada (pp. 83-85); quizá hubieran merecido un tratamiento más extenso que sirviera de contrapeso al modelo centralizado autor-obra, sobre todo considerando la reconocida relevancia del tándem intérpretes-audiencias para "definir una identidad propia de la música colonial hispanoamericana" (Waisman, 2004b, p. 122).

Desde una perspectiva puramente editorial, hay aspectos susceptibles de mejora, algunos de los cuales probablemente no son responsabilidad del autor. Una obra de este tipo, llamada a tener un amplio uso en universidades y conservatorios de todo el mundo, hubiera merecido una impresión de mayor calidad, nitidez y detalle (las carencias se hacen particularmente evidentes en los pentagramas de los ejemplos musicales, convertidos en líneas de puntos, al menos en el ejemplar utilizado para esta reseña). Elementos editoriales tan dispares como las figuras, las gráficas y las tablas quedan agrupados bajo un

bles (1780-1837). La nómina de misioneros músicos tampoco es exhaustiva, quizá porque no pueda serlo: se menciona a Pedro de Gante, Luis Berger o Anton Sepp, pero se omite a otros relevantes como Juan Vaseo [Vaisseau]. En algún caso puntual, el apéndice 1 corrige y precisa detalles con respecto a lo indicado en los capítulos. Es el caso de Pedro Bermúdez, quien no fue maestro de capilla "en la Catedral de Antequera (actual Oaxaca)" (p. 51) sino en la Colegiata de Antequera (Andalucía), y cuyo "fugaz y misterioso paso" (p. 52) por Guatemala queda esclarecido en el apéndice (p. 343). Finalmente, el Miguel Osorio [Ossorio] que Perdomo ubicó en Bogotá en el siglo XVIII, y del que se "desconoce toda información biográfica" (p. 392), probablemente se corresponda con el maestro de capilla del mismo nombre, activo de la Colegiata del Salvador de Sevilla entre 1668 y 1678. mismo rubro, el de "Figuras", del que no se ofrece un índice (tampoco se hace de los más de treinta ejemplos musicales). Además, considerando la riqueza y la originalidad de la iconografía musical colonial, el aparato gráfico del volumen resulta bastante limitado, pues se reduce a dos mapas modernos de la América española (p. 26 y p. 245), dos láminas de la archicitada crónica de Felipe Guamán Poma de Ayala (p. 66 y p. 78) y un facsímil icónico del Hanacpachap (p. 169). Una revisión final más cuidada hubiera permitido corregir pequeños detalles formales, como vacilaciones en la capitalización de determinadas palabras como "compañía" (en referencia a los jesuitas, p. 75), la ausencia de comillas de cierre en casi todas las referencias bibliográficas abreviadas que figuran en nota al pie, algunos errores en la escritura de nombres (Stephen en lugar de Steven, p. 287 y p. 450; Barroeta en lugar de Barroeto, p. 297, p. 308 y p. 318) y la falta de algunas tildes, incluida la que se deslizó en la primera palabra del resumen en la contracubierta, entre otros aspectos.

Quizá la principal (y única) reserva a la lograda empresa de Waisman se relaciona con los estrictos límites cronológicos impuestos al relato (1550-1808), consecuencia de las fronteras marcadas por los proyectos editoriales que integraron en origen los bloques 1 y 3 (explicitadas y justificadas por el autor en la introducción), pero que a la postre llevan a dejar fuera los fascinantes periodos extremos de la historia colonial, aquellos en los que se configura y descompone la organización político-social de las Indias Occidentales. Por un lado, se omite toda la primera mitad del siglo XVI, que incluye los primeros contactos euro-americanos y la posterior "conquista", momento a partir del cual se establecen las bases de la cultura colonial; se echa en falta, pues, una discusión crítica de la función del sonido y la danza durante el denominado "encuentro 
de culturas", una valoración de la terminología y las referencias musicales recreadas por los primeros cronistas (sin duda reflejo de modos de escucha europeos) y un repaso a los fundacionales proyectos de implantación de la cultura musical hispana en las esferas religiosa y secular. ${ }^{13}$

Por otro lado, quedan fuera de la narración las primeras décadas del siglo XIX, una época de profundas transformaciones y llena de paradojas, caracterizada por una fuerte pervivencia de discursos y prácticas coloniales en torno a la música. El abrupto corte en 1808, justificado como una decisión "meramente de conveniencia" (p. 14), podría resultar cuestionable al menos por dos motivos: mutila la historia colonial de territorios tan representativos como la Alta California española o las Capitanías Generales de Cuba y Puerto Rico (con gobierno colonial hasta 1898), y deja en penumbra a la última generación de compositores coloniales del continente, formados en el tercio final del siglo XVIII y activos durante las primeras décadas del siglo XIX (con las guerras de independencia hispanoamericanas como telón de fondo). Los amplios catálogos de estos maestros locales, a la vez cosmopolitas y patriotas, tienen mucho que aportar al conocimiento de las prácticas musicales en las primeras décadas de vida republicana. ${ }^{14}$ La necesidad de que futuras síntesis amplíen el marco cronológico resulta, pues, determinante para hacer un seguimiento de los usos, desusos, interacciones y transformaciones de la tradición musical colonial, de la que también formaron

\footnotetext{
${ }^{13}$ La existencia del estudio en inglés de Gary Tomlinson, The Singing of the New World: Indigenous Voice in the Era of European Contact (2007), por sofisticado que sea, no parece un motivo justificado para no tratar ese periodo, sobre todo considerando la vocación de libro de texto de la obra de Waisman.

${ }^{14} \mathrm{El}$ hecho de compartir un marco temporal y unos factores históricos y sociales comunes lleva a José Manuel Izquierdo König (2018) a agrupar a estos compositores en una misma generación que apropiadamente denomina "perdida".
}

parte una serie de actores en la distancia aquí no considerados: los compositores europeos que no viajaron a América, cuyos repertorios ampliamente conocidos e imitados- ocuparon una posición central en la praxis musical de los virreinatos.

Los comentarios anteriores no han de empañar, en modo alguno, las excepcionales aportaciones que confluyen en esta inspiradora Una historia de la música colonial hispanoamericana, que es -como acertadamente refleja el título- una de tantas posibles, y que cumple de sobra con las altas expectativas que genera. Como toda buena obra, estimula el pensamiento, abre múltiples relaciones entre conceptos y establece nuevas líneas de trabajo que merecen estudios en profundidad. Con las restricciones pero también con el potencial de un manual de síntesis adaptado a los marcos teóricos actuales, esta contribución de Leonardo J. Waisman (que sería bueno traducir al inglés y hacerla acompañar de una sucinta discografía o lista de reproducción e, idealmente, una antología de obras) hará más visible la música colonial en el paisaje musicológico internacional y facilitará la incorporación de todo un continente a los desarrollos divergentes y las trayectorias multilineales de la historia global.

\section{Bibliografía}

» Albino, R. (2016). Música colonial hispanoamericana. Mendoza: el autor.

» Baker, G. (2008). Imposing Harmony: Music and Society in Colonial Cuzco. Durham: Duke University Press.

»Bermúdez, E. (Ed.). (1988). Antología de música religiosa, siglos XVI-XVIII. Archivo Capitular, Catedral de Bogotá. Bogotá: Presidencia de la República de Colombia. 
" Cazorla, J. I. (2000). El monasterio de las monjas y la creación de los primeros poemas y música polifónica en Ibarra. Ibarra: Pontificia Universidad Católica del Ecuador.

»Cetrangolo, A. E. y Giuliani R. (1992). Bibliografía de la música colonial latinoamericana. Padua: Sociedad Española de Musicología e Instituto per lo Studio della Musica Latino-Americana durante il Periodo Colonial.

»Claro-Valdés, S. (1985). Music in Sacred and Secular Establishments of the Viceroyal Period (ca. 1492-ca. 1810) (first draft). Copia mecanografiada presentada en el encuentro regional Music in the Life of Man: A World History (Ciudad de México, 4-6 de febrero de 1985). 119 pp. [ejemplar conservado en la Pontificia Universidad Católica de Chile, Biblioteca Campus Oriente, Colecciones Especiales, 780.98 C613m 1985].

»Duncan, M. E. (1975). A Sixteenth-Century Mexican Chant Book: Pedro Ocharte's Psalterium, An(t)iphonarium cum psalmis \& hymnis (1584). (tesis de Ph.D.). University of Washington, Seattle, Estados Unidos.

"Eyzaguirre, R. (1973). Melchor Tapia and Music in the Lima Cathedral. (tesis de Ph.D.). University of Miami, Miami, Estados Unidos.

» Godoy Aguirre, M. (2004). La música en la época colonial en la presidencia y real audiencia de Quito. Quito: Empresa de Desarrollo del Centro Histórico.

»Harrison, F y J. (1973). A Villancico Manuscript in Ecuador: Musical Acculturations in a Tri-ethnic Society. In H. H. Eggebrecht y M. Lütolf (Eds.). Studien zur Tradition in der Musik. Kurt von Fisher zum 60. Geburtstang (pp. 101-119). Múnich: Emil Katzbichler.

»Housty, E. P. (1970). The Graduale Dominicale (México: Pedro Ocharte, 1576) of Juan Hernández. (tesis de Ph.D.). Catholic University of America, Washington, Estados Unidos.

»Huseby, G. V. (1993). La Bibliografía Musicológica
Latinoamericana. Revista Musical Chilena, 47(180), 60-64.

》 Izquierdo König, J. M. (2018). En busca de una generación perdida: ser compositor en lberoamérica en tiempos de independencia (1790-1850). En J. Marín-López (Ed.). Músicas coloniales a debate: procesos de intercambio euroamericanos (pp. 355-376). Madrid: Instituto Complutense de Ciencias Musicales.

"Lehnhoff, D. (1990). The Villancicos of the Guatemalan Composer Raphael Antonio Castellanos (d. 1791): A Selective Edition and Critical Commentary. (tesis de Ph.D.). Catholic University of America, Washington, Estados Unidos.

» Madsen, W. J. (1984). Mexican Mission Music: A Descriptive Analysis and Comparision of Two Seventeenth-Century Chant Books. (tesis de D.M.A.). University of Oklahoma, Oklahoma, Estados Unidos.

» Marín-López, J. (2009). Review Essay of G. Baker. Imposing Harmony. Music and Society in Colonial Cuzco. Durham, NC and London: Duke University Press, 2008. Early Music History, 28, 285-301. doi: $10.1017 /$ S0261127909000436.

»Mendoza de Arce, D. (2001). Music in IberoAmerica to 1850. A Historical Survey. Lanham y Londres: The Scarecrow Press.

» Nichols, D. C. (1975). Francisco Delgado and Classicism in Mexican Music as exhibited in the Missa a Quatro Voces. (tesis de Ph.D.). Indiana University, Indiana, Estados Unidos.

» Plaza, J. B. (1942-43). Archivo de música colonial venezolana. 12 vols. Caracas y Montevideo: Ministerio de Educación Nacional de Venezuela e Instituto Interamericano de Musicología.

»Pérez González, J. (2019). Historia y música. Comentarios sobre Una historia de la música colonial hispanoamericana de Leonardo Waisman. Revista Musical Chilena, 73(232), 138-146. Recuperado de https:// revistamusicalchilena.uchile.cl/index.php/ RMCH/article/view/55821. 
»Restiffo, M. (2010). Reseña bibliográfica de Mendoza de Arce, D. Music in Ibero-America to 1850. A Historical Survey. Lanham (Maryland) and London: The Scarecrow Press, 2011. Revista del Instituto de Investigación Musicológica Carlos Vega, 24, 439-452.

»Restiffo, M. (2019). Grupo de Musicología histórica Córdoba, informe de investigación (2010-2018). En P. E. Jaureguiberry y C Pedrotti (Eds.). Actas de la XXIII Conferencia de la Asociación Argentina de Musicología y XIX Jornadas Argentina de Musicología del Instituto Nacional de Musicología "Carlos Vega" (pp. 353364). Buenos Aires: Asociación Argentina de Musicología e Instituto Nacional de Musicología Carlos Vega.

» Restrepo, M. (1996). Juan de Herrera. Tres misas de difuntos. Caracas: CONAC, Fundación Vicente Emilio Sojo y COLCULTURA.

»Stevenson, R. M. (1968). Music in Aztec and Inca Territory. Berkeley y Los Ángeles: University of California Press.

»Stevenson, R. M. (1984). The Music of Colonial Spanish America. In L. Bethell (Ed.). The

Cambridge History of Latin America. Vol. 2. Colonial Latin America (pp. 771-798). Cambridge: Cambridge University Press.

"Stevenson, R. M. (2020, en prensa). Music in the American Viceroyalties. In M. Kuss (Ed.). Music in Latin America and the Caribbean: An encyclopedic history. Vol. 3: Source Readings in Music History: Latin America. Digital Monograph Press.

» Tomlinson, G. (2007). The Singing of the New World: Indigenous Voice in the Era of European Contact. Cambridge: Cambridge University Press.

»Waisman, L. J. (1988). The Ferrarese Madrigal School in the Mid-Sixteenth Century (tesis de Ph.D.). 4 vols. University of Chicago, Chicago, Estados Unidos.

»Waisman, L. J. (1991). Música misional y estructura ideológica en Chiquitos (Bolivia). Revista Musical Chilena, 45(176), 43-56.
Recuperado de https://revistamusicalchilena. uchile.cl/index.php/RMCH/article/view/13906.

»Waisman, L. J. (1998). ¿Cómo escuchar la música colonial latinoamericana? Música e Investigación, 2, 99-107.

»Waisman, L. J. (2004a). La América española: proyecto y resistencia. En J. Griffiths y J. Suárez Pajares (Eds.). Políticas y prácticas musicales en el mundo de Felipe II. Estudios sobre la música en España, sus instituciones y sus territorios en la segunda mitad del siglo XVI (pp. 503-550). Madrid: Instituto Complutense de Ciencias Musicales.

»Waisman, L. J. (2004b). La música colonial en la Iberoamérica neo-colonial. Acta Musicologica, 76(1), 117-127.

»Waisman, L. J. (2009). La biografía musical en la era post-neomusicológica. Música e Investigación, 23, 177-194.

»Waisman, L. J. (2014). La música en la América española. En J. M. Leza (Ed.). Historia de la música en España e Hispanoamérica. Vol. 4: La música en el siglo XVIII (pp. 556-652). Madrid: Fondo de Cultura Económica de España.

» Waisman, L. J. (Ed.). (2015). Un ciclo musical para la vida en misión jesuítica: los cuadernillos de ofertorios de San Rafael (S. XVIII). 3 vols. Córdoba: Editorial Brujas.

»Waisman, L. J. (2016). Periodización historiográfica y dogmas estéticos: un ejercicio sobre villancicos coloniales. Resonancias, 20(38), 55-69. Recuperado de http://resonancias.uc.cl/ es/N\%C2\%BA-38/periodizacion-historiograficay-dogmas-esteticos-un-ejercicio-sobrevillancicos-coloniales.html.

»Waisman, L. J. (2017). Grandes relatos sin metarrelatos. Revista Argentina de Musicología, 18, 17-26. Recuperado de http://ojs. aamusicologia.org.ar/index.php/ram/article/ view/212. 


\section{Biografía / Biografia / Biography}

\section{Javier Marín-López}

Doctor y Magíster en Musicología por la Universidad de Granada y Profesor Titular de Música en la Universidad de Jaén (España). Ha estudiado diversos aspectos de la cultura musical latinoamericana y española durante los siglos XVI al XIX, con particular énfasis en sus procesos de intercambio transatlántico en el más amplio contexto europeo. Entre sus publicaciones recientes se cuentan artículos y reseñas en prestigiosas revistas internacionales y la edición de los libros Músicas coloniales a debate. Procesos de intercambio euroamericanos (Madrid: Instituto Complutense de Ciencias Musicales, 2018) y El villancico en la encrucijada: nuevas perspectivas en torno a un género literario-musical (siglos XVXIX) (Kassel: Reichenberger, 2019; coed. Esther Borrego). En la actualidad es director de la Revista de Musicología, coordinador de la Comisión de Trabajo "Música y Estudios Americanos" (MUSAM) de la Sociedad Española de Musicología y dirige el Festival de Música Antigua de Úbeda y Baeza (FeMAUB). Además, es miembro del equipo de investigación de la plataforma digital Books of Hispanic Polyphony IMF-CSIC, https://hispanicpolyphony.eu 


\title{
Conozco la canción. Melodías populares en los cines posclásicos de América Latina y Europa
}

\author{
Piedras, P. y Dufays, S. (Comps.). (2018). Buenos Aires: Libraria. 352 páginas.
}

\section{Angélica Adorni}

Instituto de Artes del Espectáculo,

Facultad de Filosofía y Letras, Universidad de Buenos Aires, Buenos Aires, Argentina angelicaadorni@gmail.com

El presente libro reúne veintiún artículos originados en un coloquio internacional sobre cine y canción realizado en Bélgica en 2016. ${ }^{1}$ Los mismos comprenden un amplio abanico de temáticas, estéticas y enfoques, unidos por el interés de estudiar el papel de la canción popular en los cines posclásicos de Europa y Latinoamérica. Por posclásico refieren, ampliamente, a filmografías surgidas a nivel internacional a partir de 1960, tanto de impronta autoral como del mainstream, en un largo período que llega hasta nuestros días. Los sesenta acarrean un quiebre en el sistema de producción industrial que sufre transformaciones debido a factores como "la expansión de la televisión, el agotamiento de la producción fílmica serializada a través de grandes estudios-factorías, la aparición de las nuevas olas y la creciente consolidación de modalidades alternativas e independientes de realización en el marco del quehacer cinematográfico" (p. 7). Se observa además en esa década el crecimiento de una sinergia comercial entre el nuevo cine y las industrias en torno a la música popular, en un contexto de particulares tensiones y redefiniciones en la cultura popular (p. 12).

\footnotetext{
${ }^{1}$ El coloquio "La canción en los cines de América Latina y de Europa (1960-2010): variantes genéricas, hibridaciones estéticas y valores trasnacionales" fue organizado por instituciones belgas en colaboración con la Universidad de Buenos Aires. En abril de 2020 estaba prevista su segunda edición en Buenos Aires, pero fue reprogramada. Los autores pertenecen a universidades u organismos de Argentina, Brasil, Francia, España y Bélgica.
}

El libro propone entonces centrarse en el análisis del uso de la canción -y especialmente de la canción popular- en el discurso fílmico, dejando a un costado la observación de otras formas musicales como la banda sonora instrumental extradiegética o el análisis del musical como género cinematográfico, objetos ambos ya suficientemente estudiados, particularmente en el período del cine clásico.

El prólogo a cargo de los editores adelanta cuestiones que atravesarán los capítulos. Las canciones son consideradas "vehículos de discursos" (p. 10), cuyas significaciones culturales constituyen lugares cruciales de articulación e interrogación de identidades y representaciones generacionales, raciales, sexuales, nacionales, translocales, entre otras. La inclusión de una canción establece muchas veces un pivote en la trama fílmica, cuya función varía en cada caso: pausar o hacer avanzar la acción, marcar un comentario o un contrapunto en la diégesis, brindar información sobre el contexto o la subjetividad de los personajes, fomentar la identificación o el distanciamiento del espectador para con la historia, entre otras. Es así que las posibilidades de análisis son muchas, pudiendo poner el peso en el ángulo estético-narrativo (orientando la mirada hacia el interior del texto fílmico), como en el aspecto histórico-cultural, al tomar en cuenta referencias extratextuales que nos brindan información sobre la producción, circulación o recepción de la película y las músicas, 
o sobre imaginarios y valores connotados por las canciones, los directores, actores o intérpretes, situando espacio-temporalmente a los objetos analizados. Por otra parte, el tratamiento de piezas de muy diversa índole permite reexaminar dicotomías que han marcado los estudios canónicos del cine y el arte, como la que opone cultura de elite a cultura popular o de masas, o los binomios que enfrentan el cine comercial al de autor, o el cine espectáculo al narrativo, así como otras categorías que deben ser revisadas en pos de crear zonas de análisis más porosas y flexibles.

El libro establece tres secciones, si bien los artículos trascienden muchas veces sus alcances temáticos. La primera, "Inquisiciones teóricas e históricas sobre la canción en el cine", agrupa ensayos que, aun partiendo de casos específicos, "formulan visiones panorámicas o conceptuales de las múltiples dinámicas de la canción en el cine" que pueden servir al lector como "plataformas para caracterizar fenómenos amplios y complejos que modelizan el territorio teórico" de dicho campo de estudios (p. 15). En esta línea abre el capítulo de Phil Powrie, quien plantea -inspirado en la "imagen cristal" de Deleuzela noción de "canción-cristal" para denominar al momento musical cumbre del film, donde el espectador alcanza un punto culminante de iluminación a partir de la potencia evocadora de una canción que logra fusionar tiempo pasado y presente. ${ }^{2}$ Por su parte, Dominique Nasta recorre diacrónicamente obras de cineastas europeos y latinoamericanos (desde los sesenta hasta expresiones contemporáneas del cortometraje, el videoclip y la serie televisiva) para pensar aspectos generales del uso de canciones en tanto potenciadores de sentido y espacios autónomos de significación que añaden valor al discurso fílmico. El artículo de Guilherme Maia también

\footnotetext{
${ }^{2}$ La noción "canción-cristal” será recurrente en otros capítulos.
}

reflexiona sobre distintas posturas teóricas en torno al uso de la canción como recurso cinematográfico, para abordar luego tres casos del cine comercial brasilero de la década de los noventa, que reflejan la importancia de la tradición cancionística en ese país.

En la misma sección, pero en línea más histórica, Ricardo Manetti se acerca a nuestras latitudes para tratar la construcción de los nuevos ídolos juveniles en el cruce de la naciente televisión, el cine y la industria discográfica a comienzos de 1960. Las figuras de los argentinos Palito Ortega y Sandro -exportables al mercado hispanoamericano- le permiten discutir cuestiones de estereotipia, modernidad y consumo, control social e identificación generacional a través de la música en un marco global de profundas transformaciones. También Fernando Carmena Barrachina se ocupa de la difusión mediática de la canción "More" (Riz Ortolani), a partir de su inclusión en el documental italiano Mondo Cane a comienzos de 1960, lo que le permite una mirada cruzada entre el mundo cinematográfico y el discográfico-musical, en un momento en que el uso de la canción aparece como pieza fundamental del diseño de la banda sonora, alternativa sólida al hegemónico score orquestal del modelo clásico de Hollywood.

Dos autores se ocupan del ámbito español en este apartado. Mientras Marianne Bloch-Robin se centra en forma pormenorizada en la obra del director Carlos Saura, María Luisa Ortega realiza un recorrido por los vaivenes del musical y la canción en el cine español desde los sesenta hasta principios del siglo XXI, planteando que las canciones movilizan un ejercicio de la memoria histórica y constituyen un repositorio cultural del que el cine contemporáneo echa mano. Martín Barnier se retrotrae más en el tiempo para insistir en la histórica asociación entre cine y canción, dos artes populares ligadas ya desde fines del siglo XIX. El 
autor repasa la evolución de dispositivos tecnológicos relacionados con la imagen en movimiento y la grabación sonora, para finalmente centrarse en la filmografía de la Nouvelle Vague.

La segunda sección del libro agrupa siete capítulos bajo el título "Pugnas, indeterminaciones y celebraciones entre lo popular y lo masivo". Los tres primeros textos abordan la cuestión de los teleídolos, la cultura yeyé y la nueva sociedad de consumo de los sesenta. Marina Díaz López se centra en las películas que la cantante y actriz española Rocío Durcal realizó bajo la dirección de Luis César Amadori, productos que combinaban una impronta tradicional con contenidos que reflejaban los cambios y las problemáticas sociales del momento, y lograban un alto grado de identificación, aceptación y difusión en el mercado hispanoamericano. El artículo de Dana Zylberman retoma la figura de Durcal en el análisis de dos coproducciones argentino españolas protagonizadas por Palito Ortega, y centra su atención en la selección de canciones, lanzamientos discográficos y editoriales y otras estrategias publicitarias que favorecieron la circulación y éxito de los filmes. Similares tópicos aborda Elina Adduci Spina para el caso de El club del clan, en un agudo análisis que cuestiona preconceptos y valoraciones comunes respecto de estos repertorios. Otro aspecto de la cultura popular argentina es abordado por Tamara Accorinti en su estudio sobre la obra infantil de Manuel García Ferré. Allí analiza las intersecciones entre comedia musical y melodrama, el star sistem animado, y las estrategias de enunciación para transmitir conductas normativas y valores de la hegemonía cultural y reforzar así la asimilación de la ideología dominante a través de la canción, "inmersión sensorial” inmediata para el público infantil (p. 238).

La mirada se desplaza hacia Latinoamérica en el texto a cargo de los editores Piedras y Dufays, que analizan dos películas de la década del setenta, mexicana una y venezolana la otra, ambientadas en el mundo del cabaret nocturno. Ya sobre filmografía de nuestro siglo, Lucía Rodríguez Riva reflexiona acerca de la hibridez de la cultura latinoamericana y las pujas en el campo de lo popular en su análisis pormenorizado de Miss Tacuarembó, filme uruguayo barroco, lúdico y exuberante que trata las contradicciones de una chica de pueblo al intentar hacerse lugar en el universo del espectáculo. Disquisiciones teóricas de similar tenor presenta el artículo de Rita De Maeseneer. Allí, las comedias dominicanas contemporáneas y sus canciones le sirven para discutir estereotipos e imaginarios sobre Centroamérica, construida como geografía erotizada desde los inicios mismos de su colonización.

Por último, la sección "Políticas y afectos de la canción" reúne seis ensayos que indagan el poder de interpelación de la canción en filmografías de distinto origen y talante. Si Mónica Tovar-Vicente analiza los variados usos de canciones en la múltiple obra de Pedro Almodóvar; José Ángel Lázaro López, en cambio, focaliza su mirada en el sentido mítico y la eficacia dramática de una nana tradicional anónima utilizada en el corto Alumbramiento del español Víctor Erice. Por su parte, Pietsie Feenstra utiliza la noción de posmemoria para analizar películas que abordan el silenciamiento. Propone dos subcategorías para la canción-cristal: "canción-silencio" y "canción-eco", que le sirven para conceptualizar aquellas canciones que expresan lo que no se ve y lo que no dicen sus protagonistas, carentes de voz política. Magalí Kabous observa aspectos del sincretismo cultural cubano tanto en la recurrente utilización de una canción que condensa múltiples significaciones ("Quiéreme mucho"), como en el análisis de un musical que encarna las disputas y contradicciones identitarias y religiosas en la isla. 
Finalmente, las argentinas María Valdez y Julia Kratje despliegan una mirada desde los estudios género al tratar cuestiones de erotismo, deseo, placer, performance corporal, sexualidad, mandatos sociales. Valdez analiza tensiones en torno a la maternidad en la historia de tres mujeres en el filme Mía, en diálogo con la utilización de la canción "Zamba para no morir". Kratje se sirve de herramientas teóricas surgidas del reciente giro afectivo vivenciado en las ciencias humanas y sociales y examina operaciones de desplazamiento en las voces y en las músicas del filme Ana y los otros. Si bien la perspectiva de género no abunda en el libro, se halla presente con anterioridad en el análisis de Díaz López sobre la figura de Rocío Durcal (y con ella, la irrupción del colectivo femenino en el espacio público de los sesenta) y en el de Adduci Spina, donde relaciones tradicionales de género, autoridad institucional y amor romántico son abordados en canciones de El club del clan. También la mirada sexualizada de Centroamérica plasmada por De Maeseneer toca dicha problemática.

La propuesta del libro, por su variedad temática, resulta entonces cautivadora para lectores interesados en el cine, la música o las artes en general, profesionales del área o simplemente entusiastas. Los autores -más vinculados al ámbito cinematográfico que al musicológico- no priorizan el tratamiento específicamente musical del material. Sin embargo, el abordaje implica una novedad y brinda un valioso aporte al establecer puentes disciplinares y tratar objetos que aún no han sido estudiados con seriedad por la musicología, como por ejemplo las músicas masivas de las nuevas olas de 1960. Contextos y discusiones teóricas emergen naturalmente en los análisis, brindando ricos telones para examinar músicas populares de variado tipo y origen, sea en su aspecto histórico, social, estético. El libro propone así pensar el heterogéneo uso de la canción en el cine, cuyo poder de inmediatez la convierte, con toda su capacidad de evocación, en protagonista y articuladora de una compleja red de afectos, identidades y significados, integrando lo individual en lo colectivo.

\section{Biografía / Biografia / Biography}

\section{Angélica Adorni}

Licenciada y Profesora en Enseñanza Media y Superior en Artes (orientación Música) por la Facultad de Filosofía y Letras de la Universidad de Buenos Aires. Actualmente realiza estudios de Doctorado en Historia y Teoría de las Artes (FFyL-UBA) y es becaria doctoral UBACyT con un proyecto que aborda el análisis musical e histórico-social de la canción popular litoraleña argentina en la década de 1960. Se ha desempeñado como docente de música, historia y estética en distintos niveles educativos. Actualmente es profesora de Historia de la música popular argentina y latinoamericana, y de Etnomusicología latinoamericana en el Conservatorio Superior de Música "Manuel de Falla" de la Ciudad de Buenos Aires. Como investigadora auxiliar trabajó entre 2011 y 2013 en el Instituto Nacional de Musicología "Carlos Vega" para el proyecto Antología del Tango Rioplatense Vol. 2 (1920-1935). Es profesora en el área de Extensión de FFyLUBA, dictando cursos de Historia de la música popular abiertos a la comunidad. Ha presentado ponencias vinculadas a la música argentina en reuniones científicas del país y Latinoamérica. Publicó capítulos de libros, artículos y reseñas en medios especializados, focalizados en el tango y la música popular argentina de raíz folclórica. 


\section{Southern Rock Opera}

Fertel, R. (2018). Nueva York: Bloomsbury Academic. 152 páginas.

\section{• Luis Miguel Machín Martín \\ Universidad de La Laguna, San Cristobal de La Laguna, España lmachinm@ull.es}

Hay pocas regiones en Norteamérica que contengan más contradicciones culturales, artísticas y sociales que el llamado Sur de Estados Unidos. Allí se condensan una serie de cuestiones que componen parte del núcleo ideológico y político del país, como el nacionalismo, el racismo latente o la herencia histórica del bando confederado, pero también otros asuntos más positivos como el nacimiento de la música country y el jazz o el desarrollo de importantes corrientes de la música folk desde hace décadas.

En ese contexto tan complejo aparece la banda de country rock Drive-By Truckers en 1996, con Patterson Hood y Mike Cooley como líderes. Desde su origen, la banda ha publicado doce álbumes de estudio y se ha ganado una buena reputación gracias a su mezcla entre tradicionalismo musical -el tan valorado respeto por el género americana-y progresismo ideológico.

El libro Southern Rock Opera, escrito por Rien Fertel, con título homónimo de uno de los discos de Drive-By Truckers, precisamente analiza ese álbum, publicado en septiembre de 2001 -poco después del atentado de las torres gemelas-. Esa obra había sido un proyecto ambicioso en el que la banda lanzaba una ópera rock con el propio género del rock sureño como asunto temático principal, con Ronnie Van Zant -líder y vocalista de Lynyrd Skynyrd hasta su muerte en accidente de avión-y Neil Young como figuras destacadas y guías en todo el trayecto que recorre el libro. La salida de esta obra musical supuso un punto de inflexión en la carrera del grupo, puesto que les situó como una de las bandas más destacadas del género, pese a su relativo poco éxito comercial.

Rien Fertel, aprovechando el contexto que rodea a este disco, explora una serie de temas alrededor de Drive-By Truckers, de la vida de sus miembros principales -los mencionados Hood y Cooley-, de la historia de este género musical y de la cultura del sur de Estados Unidos, sin la cual Southern Rock Opera no tendría sentido y sería una colección de canciones vacías, para componer algo así como una pequeña biblia del rock sureño, que pese a ser un homenaje de forma abierta, no es acrítico.

El libro está estructurado en dos actos, al igual que el disco de Drive-By Truckers, pero los capítulos no se corresponden con sus canciones, sino que se construyen en torno a anécdotas, sucesos históricos y lugares que combinan la trayectoria de la banda con la genealogía musical y la geografía del Sur -Southland, como la denomina el propio Fertel- y cómo se relacionan con la música del grupo de Hood y Cooley. Así, el recorrido está compuesto, esencialmente, en torno a dos figuras, como ya se ha comentado: Ronnie Van Zant, de Lynyrd Skynyrd, y Neil Young, que a su vez son los protagonistas de la canción Ronnie \& Neil, segunda pieza del primer acto del álbum. No obstante, también se analiza la figura de Duane Allman, guitarrista de los Allman Brothers, que podría considerarse como la tercera pieza de personajes fundamentales del rock sureño, al margen 
de muchos otros músicos y productores que conformaron el tejido musical y artístico de ese sur de los años 60 en adelante, como los recientemente fallecidos Bruce Hampton y Rick Hall o el bajista David Hood, padre de Patterson Hood.

El libro es, además, un viaje casi antropológico por la construcción de la identidad del Sur y cómo esa identidad ha resonado en su música, haciendo de la región un lugar único y muy representativo para un conjunto de la población norteamericana. En ese sentido, es interesante observar cómo el autor del libro expone las contradicciones del Sur y de su música, cómo hay una combinación del conservadurismo tradicional del sur con un espíritu abierto donde paree que cualquier cosa es posible, y donde surgen figuras que representan la americanidad como la de Van Zant, pero que también permite que surjan grupos como Drive By-Truckers. En palabras de Fertel: "Esta dualidad explica los paralelismos históricos del jazz y Jim Crow. Ilustra cómo un lugar puede alzar a Martin Luther King Jr. y al Ku Klux Klan. Conecta la famosa creencia en la hospitalidad sureña con su desconfianza [...] hacia los desconocidos" (p. 6). ${ }^{1}$ El libro de Rien Fertel explica, además, cómo Drive-By Truckers recoge toda esa tradición sonora y lírica con respeto y la reinterpreta en clave progresista, denunciando injusticias y retratando a la clase obrera americana con sus miserias y luchas personales -Dead, Drunk and Naked y Moved, pistas números 4 y 11, respectivamente, del Acto I, o Women Without Whiskey, pista número 3 del segundo acto de Southern Rock Opera, serían ejemplos de esto.

Pero, además, Fertel plantea cuestiones como dónde están los límites de lo que puede

\footnotetext{
1"This duality explains the historic parallels of jazz and Jim Crow. It illustrates how a place can give rise to Martin Luther King Jr. And the Ku Klux Klan. It connects the region's famed gospel of southern hospitality with its distrust [...] of outsiders" (p. 6).
}

considerarse como música sureña: "El problema es cómo construir una definición funcional del rock sureño que incorpore a todas las bandas desde los Allmans hasta ZZ Top"2 (pp. 41-42). Esta cuestión tiene una amplia problemática, empezando por la definición geográfica de Sur en Estados Unidos, que compone una serie de estados del sur del país pero que no siempre es un conjunto cerrado de regiones: "El hecho es que la geografía del Sur ha sido una cuestión traicionera desde la década de 1760. Desde entonces, los sureños no se han puesto de acuerdo en dónde empieza y termina el Sur". Y remata afirmando que "El sur, donde quiera que esté, no cuenta toda la historia del Sur"3 (p. 42).

Al igual que hace el álbum, el libro no rechaza el debate sobre el racismo y la lucha por los derechos civiles en el sur, y glosa algunos terribles sucesos como el atentado de septiembre de 1963 a una iglesia baptista de la ciudad de Birmingham, en el que cuatro niñas de raza negra fueron asesinadas con una explosión de dinamita que había sido colocada en el edificio (p. 55). A Birmingham, precisamente, dedica la banda una canción en Southern Rock Opera, correspondiente con la sexta pista del Acto I. Sin embargo, ese repaso histórico no se detiene ahí y también aparecen personajes tan dispares como George Wallace, gobernador de Alabama durante cuatro legislaturas, político racista y segregacionista, o los escritores William Shakespeare y Herman Melville, el músico Frank Zappa, el expresidente Jimmy Carter o el periodista Tom Wolfe.

\footnotetext{
2 "The problem is how to build a working definition of southern rock that incorporates every band from the Allmans to ZZ Top" (pp. 41-42).

3 "The fact is, the geography of the South has been a tricky subject since [...] the 1760s. Since then, southerners have not agreed on where the Southland begins and ends". [...] "The South, wherever that is, does not tell the whole story of the South".
} 
Además, siguiendo ese camino que conecta lo puramente artístico -la música- con el mundo que lo rodea, el autor del libro no tiene reparos en conectar qué ha sido de esa tradición musical ideológicamente conservadora de los años 60, 70 y 80 en nuestros tiempos, así, después del accidente que acabó con la mayor parte de los miembros de la banda Lynyrd Skynyrd, en su reconstrucción el grupo "gradualmente se transformó en la banda americana por excelencia. Durante la etapa del Segundo Bush, la banda se convirtió en esencial en cadenas musicales de televisión y radio" ${ }^{4}$ (pp. 116117). Es decir, un grupo que inicialmente había surgido en un determinado contexto histórico, social y geográfico y que, en cierto modo, estaba determinado por esas circunstancias, tuvo una segunda etapa de esplendor -mucho menos brillante, eso sí- al calor del apogeo de un conservadurismo de tintes sureños, con George W. Bush, ex gobernador de Texas y presidente del país, como cabeza visible de este movimiento político.

No obstante, no se pierde de vista que el objeto de estudio es el álbum Southern Rock Opera y su banda, Drive-By Truckers, por lo que dedica unas páginas íntegramente a narrar los orígenes de sus líderes, Hood y Cooley, cómo se conocieron y cómo decidieron unirse: “En 1985, Patterson Hood conoció a Mike Cooley, un guitarrista en ciernes talentoso que era delgado y tenía el pelo largo, mientras Hood era rechoncho y llevaba su pelo de chico blanco a lo afro. Aunque ambos eran guitarristas y letristas, se fueron a vivir juntos, formaron un grupo, tocaron en el sótano de la casa de la abuela de Hood y escogieron un nombre"5 (p.

\footnotetext{
4 "Gradually transformed into a quintaessentially American band. During the second Bush era, the band became a staple on country music television and radio stations" (pp. 116-117).

5 "In 1985, Patterson Hood met Mike Cooley, a talented budding guitarist as rail-thin and long-haired as Hood was stocky and white boy-afroed. Though they were both guitarists and lyricists, they moved in together, formed a band, jammed in Hood's grandmother's basement, and picked a name" (p. 76).
}

76). Así, entre las páginas 74 y 85 se condensan los inicios de Drive-By Truckers, primero bajo el nombre de Adam's House Cat, y cómo Hood y Cooley sufrieron todo tipo de complicaciones hasta consolidar la banda y convertirse en unos artistas imprescindibles de la música sureña.

En definitiva, pese a que el centro del libro de Rien Fertel es el disco de Drive-By Truckers, éste es sólo una excusa para reflexionar sobre el camino que la banda y el propio género musical del southern rock ha recorrido para llegar hasta ahí, y cómo el pasado -la trayectoria de bandas y músicos anteriores, la tradición musical del lugar y la historia, en fin, de Estados Unidos- ha ido modelando este género hasta desarrollar una serie de temas y estéticas que Drive-By Truckers han asumido y han adaptado a los nuevos tiempos y a posiciones políticas que suelen estar en las antípodas de lo sureño. En ese sentido, Fertel construye un libro multi e interdisciplinar, atravesando materias como la musicología, la historia, la antropología o la literatura, del mismo modo que Drive-By Truckers y el propio Sur se han erigido sirviéndose de varias y contrapuestas influencias.

\section{Biografía / Biografia / Biography}

\section{Luis Miguel Machín Martín}

Graduado en periodismo por la Universidad de La Laguna (España). Actualmente se encuentra doctorándose en Arte y Humanidades por la misma universidad. Sus líneas de investigación se centran en el cine asiático contemporáneo, especialmente el cine coreano -tema del que trata su tesis doctoral-, temas de los que ha publicado diversos artículos. 